\title{
Structural control strategies based on magnetorheological dampers managed using artificial neural networks and fuzzy logic
}

\section{Estrategias de control estructural basadas en amortiguadores magnetoreológicos administrados utilizando redes neuronales y lógica difusa}

\author{
Luis Lara ${ }^{1}$, José Brito ${ }^{2}$, Carlos Graciano ${ }^{3}$ \\ ${ }^{1}$ Departamento de Ingeniería Civil, Universidad Nacional de Colombia, Colombia. Orcid: 0000-0002-2718-6234. \\ Email: lualarava@unal.edu.co \\ ${ }^{2}$ Grupo Civil Engineering Department, Departamento de Engenharia Civil e Ambiental, University of Brasília, Brazil. \\ Email: jlbrito@unb.br \\ ${ }^{3}$ Departamento de Ingeniería Civil, Universidad Nacional de Colombia, Colombia. Orcid: 0000-0003-0659-7963. \\ Email: cagracianog@unal.edu.co
}

RECEIVED: December 20, 2016. ACCEPTED: February 27, 2017. FinAL Version: May 15, 2017.

\begin{abstract}
This paper presents a numerical assessment on the performance of two structural control strategies based on magnetorheological (MR) dampers. At first, a control strategy based on artificial neural networks was employed on a simple structure to control vibration. This controller combines a predictive model function to control forces and an inverse model of voltage calculation to manage the MR dampers. Secondly, a control strategy based on fuzzy logic was also used. Therefore, the controller governs the actions from a set of rules that represent the heuristics of the system to be controlled. Results achieved from the numerical simulations indicate that the performance of these two control strategies is promising and satisfactory, based on response reductions of up to $83 \%$ relative to the performance of the system without control.
\end{abstract}

KEYWORDS: Control of structures, Vibration reduction, Magnetorheological dampers, Artificial neural networks, Fuzzy logic.

\section{RESUMEN}

En este trabajo se presenta una evaluación numérica sobre el desempeño de dos estrategias de control estructural basado en amortiguadores magnetoreológicos (MR). En primer lugar, se empleó una estrategia de control basada en redes neuronales artificiales en una estructura simple para el control de vibraciones. Este controlador combina una función de modelo predictivo para las fuerzas de control y un modelo inverso del cálculo de la tensión para manejar los amortiguadores MR. En segundo lugar, se utilizó una estrategia de control basada en lógica difusa. De esta forma, el controlador gobierna las acciones de un conjunto de reglas que representan la heurística del sistema a controlar. Los resultados de las simulaciones numéricas indican que el rendimiento de estas dos estrategias de control es prometedor y satisfactorio, basado en la reducción de la respuesta de hasta un $83 \%$ en relación con el rendimiento del sistema sin control.

PALABRAS CLAVE: Control de estructuras, Reducción de vibraciones, Amortiguadores magnetoreológicos, Redes neuronales artificiales, Lógica difusa.

Este artículo puede compartirse bajo la licencia CC BY-ND 4.0 y se referencia usando el siguiente formato: L. Lara, J. Brito, C. Graciano, "Structural control strategies based on magnetorheological dampers managed using artificial neural networks and fuzzy logic", UIS Ingenierías, vol. 16, no. 2, pp. 227 - 242, Julio - Diciembre 2017. Doi: https://doi.org/10.18273/revuin.v16n2-2017021 


\section{INTRODUCTION}

Magnetorheological (MR) dampers are semi-active control devices whose operation is directly related to the rheological properties of MR fluids, especially to that one related to the possibility of changing quickly, and reversible form of a linear viscous free-flow state to a semi-solid when applying a magnetic field [1-3]. This transition is possible due to that the magnetically polarizable micrometric particles (iron particles), that are contained in the MR fluids, become in milliseconds, linear chains parallel to the field, so the fluid leaves its natural state and gains resistance to flow [2].

Based on this feature, the MR dampers are adaptable devices capable of handling variable damping forces, which makes them versatile and ideal tools for the control of vibrations in structural systems. In the concerning literature, different mathematical models have been developed in order to simulate numerically the performance of the MR dampers. According to [4], these numerical models can be divided into two major groups, non-parametric models and parametric models.

On the one hand, non-parametric models are based on the analysis of the actual performance of the MR dampers. This means that these numerical models work with a large amount of experimental data where the behavior of the device is examined on various operating conditions to reconstruct the approximated behavior of the dampers under such circumstances. Non-parametric models are based on mathematical approximations [5- 8], artificial neural network [9-12], neuro-fuzzy systems and genetic algorithms [13-16], among others.

On the other hand, parametric models consist of a series of mechanical components such as springs, dampers and masses trying to emulate the complex behavior of MR dampers. Generally, the parameters of these elements are determined by the experimental setting of the actual performance of the dissipating devices. One of the first functional parametric models for MR dampers was the Bingham model proposed in [17, 18], which consisted of an element of Coulomb friction placed in parallel with a viscous damper.

Subsequently, [19] proposed a modified Bingham model, positioning it in series with a standard linear solid model. This model showed a behavior quite accurate and similar to the results obtained experimentally, although the behavior of the fluid when the velocity was close to zero was not properly emulated [3]. Finally, [20] proposed a modified Bouc-Wen model, also called phenomenological model. This model consists of a spring positioned in parallel with a damper installed in series to a model reproducing hysteretic systems (Bouc-Wen model). The development of this model represented an important step forward in the development of numerical applications aimed at working with MR dampers, since a properly phenomenological model reproduces the nonlinearities of the dampers and their numerical results greatly resemble the experimental ones that can be obtained with this type of devices.

As mentioned above, several numerical models have been developed to understand the behavior of MR dampers. Once the dampers are modeled, the research has focused on the planning and development of control techniques that can take advantage of the main characteristics of these mechanisms. This includes the treatment of structural control systems that use MR dampers. Therefore, research works focused on the control of structures dealt with the management of systems through various control algorithms based on mathematical models, fuzzy logic, genetic algorithms and neural networks [4, 9, 21-30].

This work aims at developing two structural control projects focused on the use of intelligent systems. The first control strategy consists of a dual system based on a prediction model and an inverse dynamic model, developed from artificial neural networks (ANN). Thereafter, the second control strategy implemented is based on fuzzy logic (FL), which uses heuristic knowledge from the system to be managed in order to generate control actions based on a set of preset rules. Finally, to compare the performance of the control strategies studied, a numerical study is conducted to evaluate their performance and infer characteristics and behaviors related to the operation and efficiency of each controller.

\section{ARTIFICIAL NEURAL NETWORK-BASED CONTROLLER}

The first control strategy to be described is a controller based on a predictive model and an inverse dynamic model. These models were developed by NARX-type (nonlinear autoregressive exogenous model) artificial neural networks (ANN) that are based on a nonlinear autoregressive model with exogenous inputs. These networks are of a type of recurrent network with global feedback links and whose basic construction block is based on multilayer perception. This type of network is commonly referred to in the literature as a dynamically managed recurrent network because of their use as inputoutput mapping networks [31]. By definition, the input space of a network of this class is mapped to an output space, causing the network to temporarily respond to an externally applied input signal. Furthermore, the 
application of feedback links allows the networks to obtain representations of state, which make them proper devices for application to nonlinear dynamic systems with the potential to significantly reduce computational cost.

The primary objective of the ANN-based control algorithm is to calculate the optimal control force to be applied by the energy dissipation mechanism (MR damper) so that it reduces the movement of the protected structure as much as possible. Nevertheless, the control project should also determine the voltage to be applied on the controller, as the increase or decrease in the forces produced by the damper is indirectly controlled by the voltage applied to the device. To determine these two fundamental parameters, i.e. the optimal force and voltage, two properly trained NARX networks are used. The first network simulates a predictive model responsible for determining the optimal control force required by the MR damper to minimize, as efficiently as possible, the structural vibrations when external forces act on the structure's base. In turn, the second network works as an inverse model; i.e. the network determines the input to the control plant with the delayed output of the system. Thus, the second network defines the proper voltage applied to the control device so that the latter applies a force to the structure close to the optimal force calculated by the first neural system. Figure 1 shows the schematics of the ANN-based controller.

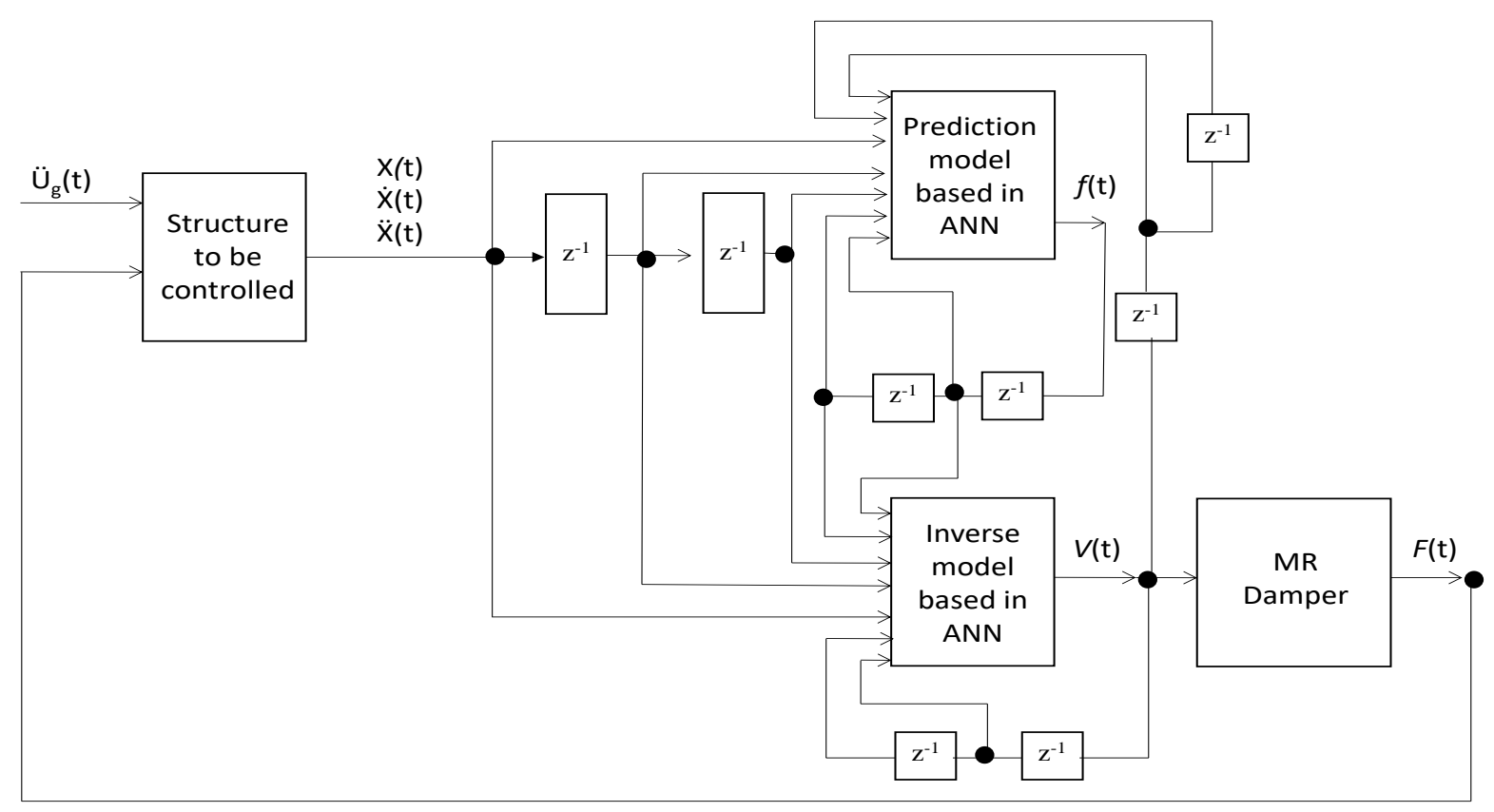

Figure 1. ANN-based control system. Source: The authors.

The optimal force-prediction model used in the control project consists of a completely interlinked NARX-type neural network containing a layer of sensory units composed of fifteen input signals and a bias, a layer of computational processing composed of sixteen hidden neurons and a layer of results composed of a single output. Based on the results obtained in [32], the delay in the network inputs was of the second order. Thus, the selected input values (displacement, velocity and acceleration of the floor level of the structure, and the voltage) and the output values of the model feeding back to the system were delayed by times of one and two units, respectively.

The inverse model for determining the voltage to be applied to the MR damper also consists of a completely interlinked NARX network. Similarly to the predictive model, the network is configured with a layer of sensory units composed by fifteen input signals and a bias, a layer of computational processing composed of sixteen hidden neurons and a layer of results composed of a single output. The neural network input layer of the inverse model manages the displacement, velocity and acceleration values of the first floor of the structure, which are added to the values of optimal control force calculated by the predictive model and to the feedback of the recurrent network itself with the output value (voltage).

The activation functions used by the inverse model were exactly the same as those used by the predictive model; i.e. fifteen hyperbolic tangent sigmoid functions were applied to the input-processor step, and one linear function was applied to the processor-output path. The 
Levenberg-Marquardt algorithm [33,34] was the training algorithm used to adjust the weights of synaptic connections between neurons in the proposed models. A schematic of the neural networks applied to the force prediction model and the inverse model for the

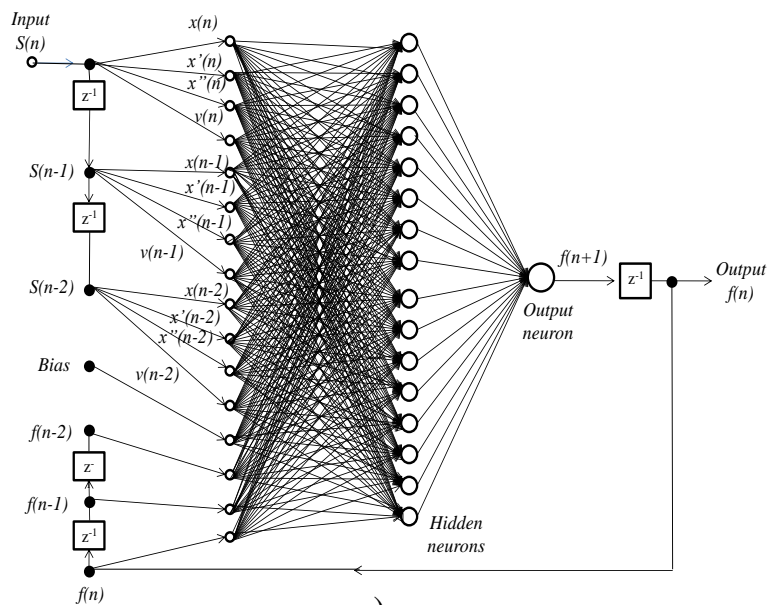

a) determination of the voltage is presented in Figure 2. Details of the definition, setup, training and validation of the NARX networks used for both the prediction model and the inverse model can be found in [30, 35].

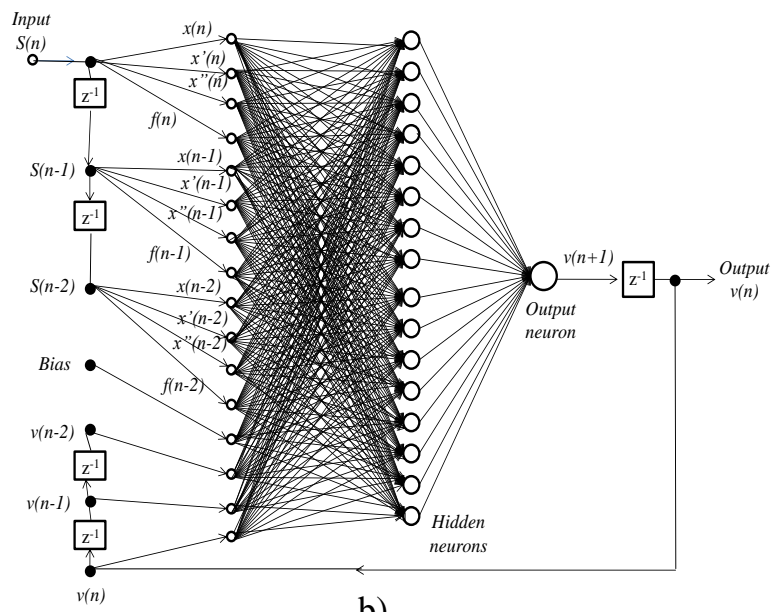

b)

Figure 2. NARX networks applied to controller: a) force prediction model and b) inverse model of voltage determination. Source: The authors.

\section{FUZZY LOGIC-BASED CONTROLLER}

The second control strategy analyzed in this study is based on fuzzy logic. This controller is based on if-then rules that correlate the plant inputs of the system with the desired outputs. In [36, 37], it was described a fuzzy logic (FL) control process consisting of three fundamental steps: fuzzification, decision-making and defuzzification. In the first step, fuzzification, the controller converts the system inputs into fuzzy linguistic values with the use of pertinence functions; i.e., the numerical input values are converted into linguistic values. Once the system is fuzzified, the controller makes decisions based on programmed control rules while always considering the information in the system to then determine the optimal output linguistic value. Finally, the defuzzification consists of converting the optimal linguistic output value into a numerical value corresponding to the command signal that will act directly on the MR dampers. Figure 3 presents the schematics of the control project based on fuzzy logic.

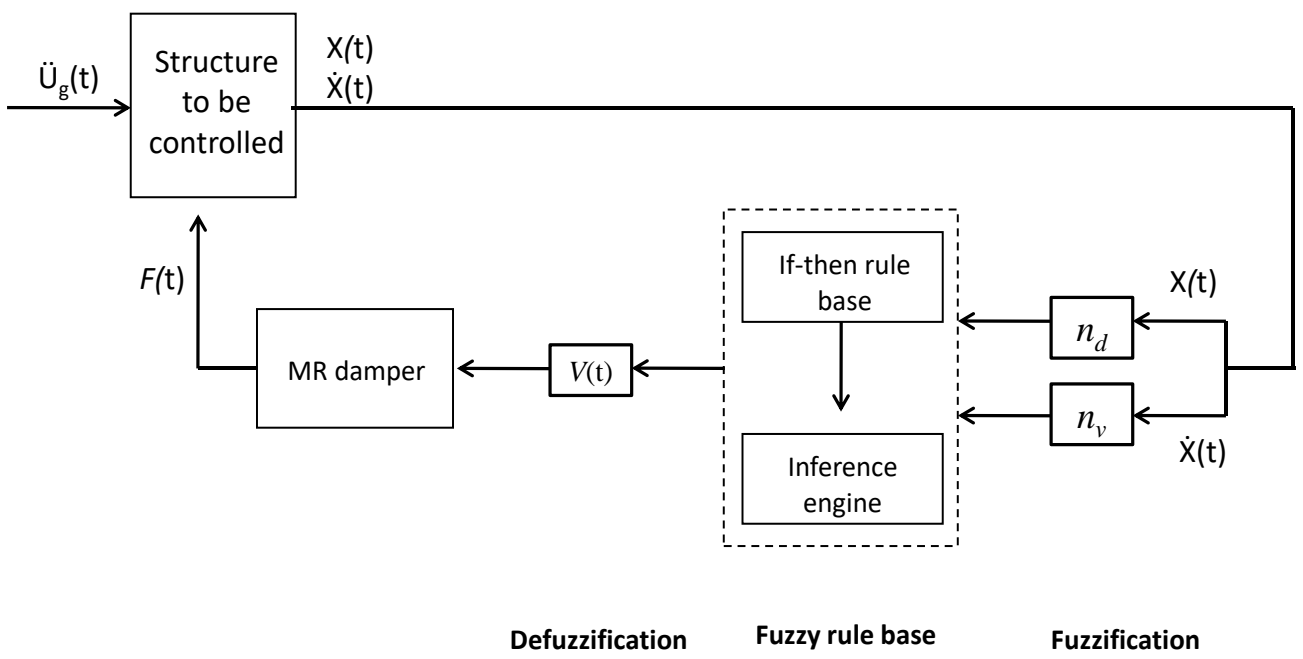

Figure 3. Control system based on fuzzy logic. Source: The authors. 
The controller described in this section is mostly based on the studies developed in [4, 24]. Based on these studies, the displacement and velocity of the first floor of the structure were used as input variables for the controller, and the output variable was the voltage applied to the MR dampers.

Fuzzification of the controller input values starts by applying two linear functions, one for the displacement and another for the velocity, which are used to normalize the responses by the structure in a universe of pertinence functions with values between -1 and 1. Eqs. (1) and (2) gives expressions for the two linear functions used herein:

$$
\begin{aligned}
& n_{d}=k_{d} x \\
& n_{v}=k_{v} \dot{x}
\end{aligned}
$$

Where $n_{d}$ and $n_{v}$ are, respectively, the input values normalized in the universe of displacement and velocity pertinence functions, and $k_{d}$ and $k_{v}$ are scale factors of the displacement and velocity, respectively. Based on the analysis of certain parameters, [24] proposed Eqs. (3) and (4) for the scale factors:

$$
\begin{aligned}
k_{d} & =\frac{3}{x_{\max }} \\
k_{v} & =\frac{3}{\dot{x}_{\max }}
\end{aligned}
$$

Where $x_{\max }$ and $\dot{x}_{\max }$ represent, respectively, the maximum displacement and velocity of the structure without control and when subject to excitation. To determine the scale factors in this study, the structure in the numerical analysis was subjected to the record of standard acceleration from the Italian research project ReLUIS-DPC [28, 38]. This record was prepared beforehand by registering it in time with the magnitude according to the dimensions of the structure. Thus, it was determined that the scale factors $k_{d}=612$ and $k_{v}=20$ would be used.

Once the linear functions used to fuzzify the numerical inputs were determined, the pertinence functions for the input and output of the controller were defined. These input functions consist of seven identical triangles that overlap one another in the center of the base and are defined in the universe $[-1,1]$. In turn, the pertinence functions of the controller output (voltage) consisted of four equal triangles that also overlap one another at the center of the base and are defined in the universe of pertinence functions $[0,1]$. Note that the definition of pertinence functions of the system and its universes were created in [24], and this set of rules were adapted to the heuristics data of the system under study here. Figure 4 shows schematics of the input and output pertinence functions of the designed controller, where the fuzzy linguistic designations NL, NM, NS, ZO, PS, PM and PL stand for negative large, negative medium, negative small, zero, positive small, positive medium and positive large degrees of membership, respectively.

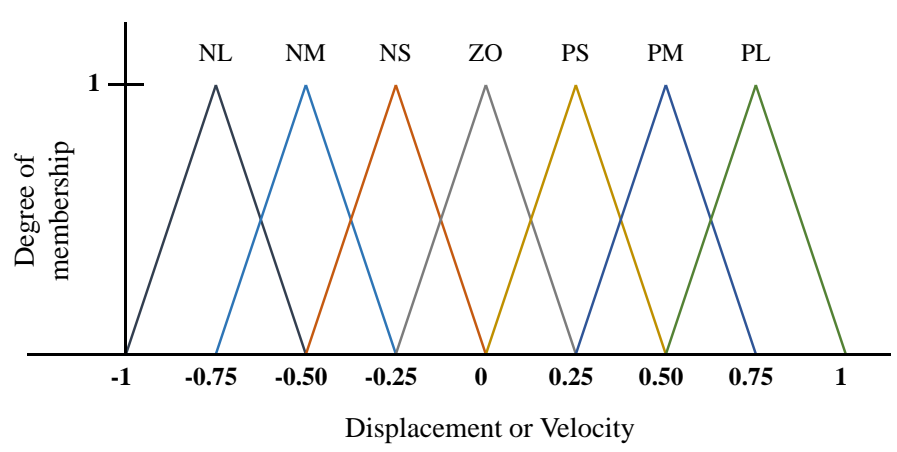

a)

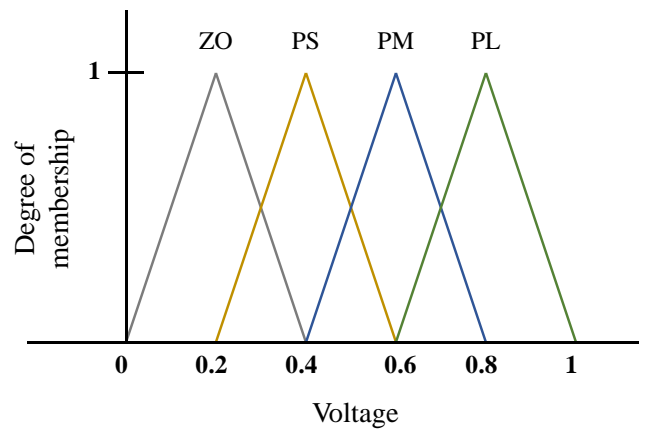

b)

Figure 4 Pertinence functions of the fuzzy controller: a) pertinence functions of controller inputs and b) pertinence functions of controller outputs. Source: The authors.

The decision-making step is executed based on an inference engine that is linked to a database and works according to the pertinence degree of the controller inputs. [24] developed a system of inference rules that allow for the calculation of the necessary voltage so that the control devices efficiently dissipate the energy that enters the structure. This system is based on the following basic principle: if the structure is out of its neutral position and its tendency of movement is to shift farther from its neutral position, then the applied voltage should increase to improve its damping capacity. However, if the structure is out of its neutral position and its tendency of movement is to approach its neutral position, then little or no voltage is applied. Table 1 presents this inference system. 
Table 1. Inference system.

\begin{tabular}{llllllll}
\hline YEL. & & & & & & & \\
DIS. & NL & NM & NS & ZO & PS & PM & PL \\
\hline NL & PL & PL & PL & PM & ZO & ZO & ZO \\
NM & PL & PL & PL & PS & ZO & ZO & PS \\
NS & PL & PL & PL & ZO & ZO & PS & PM \\
ZO & PL & PM & PS & ZO & PS & PM & PL \\
PS & PM & PS & ZO & ZO & PL & PL & PL \\
PM & PS & ZO & ZO & PS & PL & PL & PL \\
PL & ZO & ZO & Z0 & PM & PL & PL & PL \\
\hline
\end{tabular}

Source: The authors.

Pertinence degree of the controller output is determined using the least squares method, which consists of selecting the output pertinence degree equal to the lowest input pertinence degree. Finally, the defuzzification strategy starts by using the centroid method, which allows for the determination of a voltage from the overlapping areas of the output pertinence functions. The voltage obtained using the centroid method is found in the universe $[0,1]$, and it is therefore necessary to use a scale factor that maps the output values of the fuzzy universe $[0,1]$ to the real universe $[0,2.5]$. Eq. (5) gives an expression for the scale factor:

$$
V=2.5\left(\frac{5}{3} s-\frac{1}{3}\right)
$$

Where $V$ is the voltage to be applied to the MR dampers, and $s$ is the numerical value of the centroid method output. The defuzzification process of the controller was designed such that if the voltage $V$ exceeds the maximum voltage allowed by the analysis ( 2.5 volts), the maximum voltage is automatically substituted for the value determined using Eq. (5).

\section{NUMERICAL MODEL, RESULTS AND DISCUSSION}

\subsection{Numerical model}

Figure 5 shows a schematic view of the structure used in the numerical model. Accordingly, the structure consists of a two-floor building of frame type; each floor is $2 \mathrm{~m}$ tall. In a plain view, the building is a rectangle measuring $3 \mathrm{~m}$ in the $\mathrm{Y}$ direction and $4 \mathrm{~m}$ in the $\mathrm{X}$ direction. Each floor has three degrees of freedom, i.e. horizontal displacements on axis $\mathrm{X}$ and $\mathrm{Y}$ and rotation around axis $\mathrm{Z}$. The structural properties of the frame are shown in Figure 6, where the mass matrix has units of $\mathrm{kg}$ and $\mathrm{kg} \cdot \mathrm{m}^{2}$, the stiffness matrix has units of $\mathrm{N} / \mathrm{m}$ and $\mathrm{N} \cdot \mathrm{m}$ and the damping matrix has units of $\mathrm{N} \cdot \mathrm{s} / \mathrm{m}$ and $\mathrm{N} \cdot \mathrm{s} \cdot \mathrm{m}$.

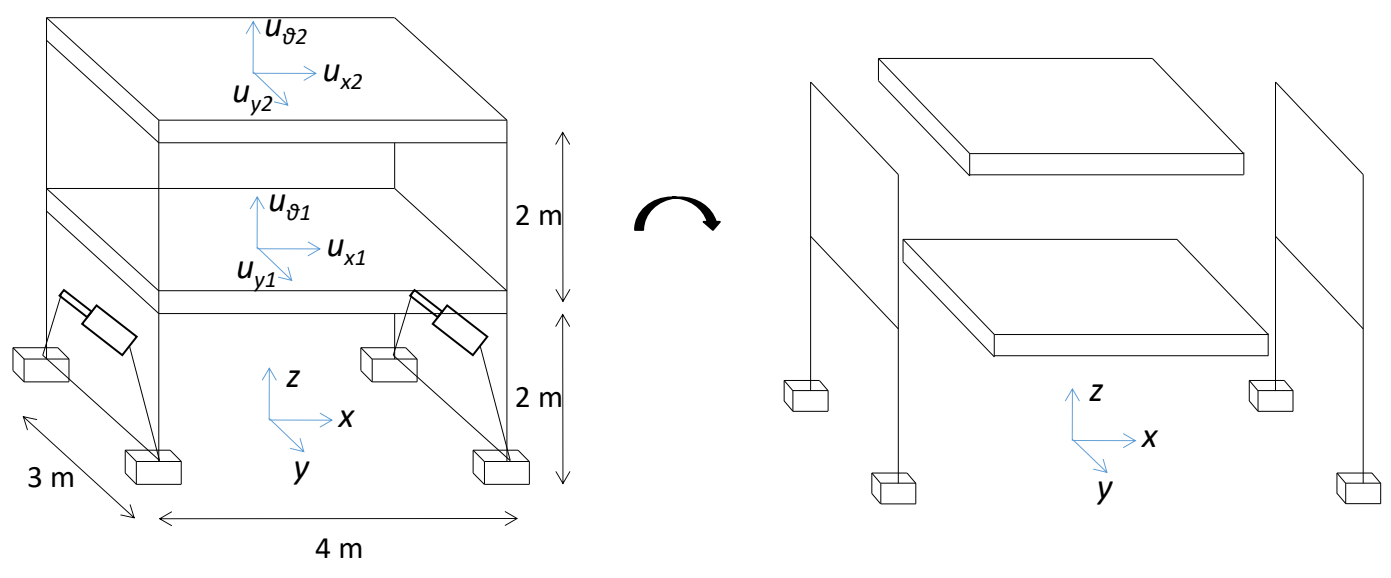

Figure 5. Structure used in the numerical model. Source: The authors.

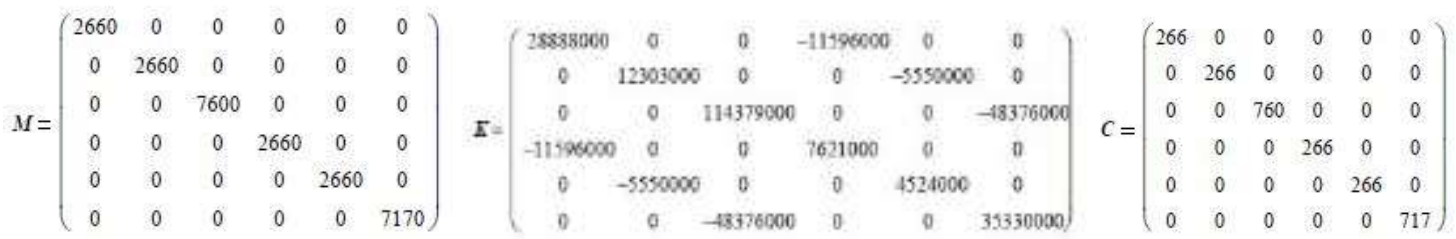

Figure 6. Structural properties of the frame. Source: The authors. 
Table 2 shows the geometry and dimensions of the structural elements used in the building shown in Figure 5. Two types of structures elements were employed, specifically commercial steel profiles type HE 140B for the pillars and IPE 180 for the beams. The slabs of the floors are composed of a concrete-coated steel plate [28, 38], this geometry is similar to the one used in [25]. Furthermore, the model includes a pair of MR RD-1005-3 [39] dampers in the base of the building, used to control the vibration of the structural system. The characteristic behavior of these devices was modeled using the phenomenological model proposed in [20]. Table 3 shows the primary properties of RD-1005-3 MR dampers, according to the technical specifications published by the manufacturer [39].

Table 2. Geometry and dimensions of the structural components.

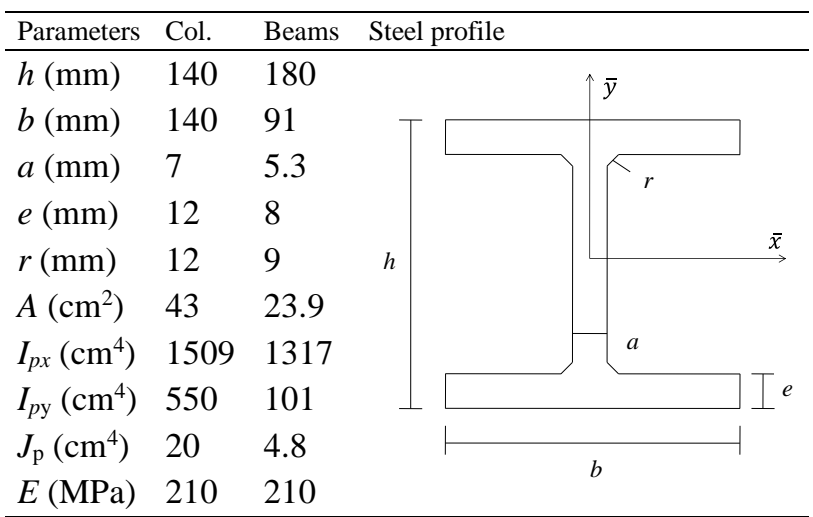

Source: The authors.
In order to apply an acceleration to the model, an acceleration record taken from [38], was applied to the base of the structure on the Y direction. This acceleration record was previously prepared by staggering it in time and magnitude, in such a way that is compatible with the dimensions of the structure, thereby resulting in a $40 \mathrm{~s}$ duration with an absolute maximum amplitude of 1.47 $\mathrm{m} / \mathrm{s}^{2}$, as shown in Figure 7.

Table 3 - Properties of the RD-1005-3 MR damper [39].

\begin{tabular}{lr}
\hline Damper properties & Values \\
\hline Extended length $(\mathrm{mm})$ & 208 \\
Compressed length $(\mathrm{mm})$ & 155 \\
Body diameter $(\mathrm{mm})$ & 41.4 \\
Maximum operating temperature $\left({ }^{\circ} \mathrm{C}\right)$ & 71 \\
Maximum extension force $(\mathrm{N})$ & 4448 \\
Maximum input current $(\mathrm{A})$ & Continuous $=1$ \\
Input voltage $(\mathrm{V})$ & Intermittent $=2$ \\
Electrical resistance at room temperature (Ohms) & $12 \mathrm{DC}$ \\
Response time (ms) & 5 \\
\hline & $<15$ \\
Source: The authors.
\end{tabular}

\subsection{Response parameter}

Figures 8, 9 and 10 shows the displacement, velocity and acceleration records of the structure (time domain) with time for the cases without control (Not controlled), case of fuzzy logic control (Fuzzy), and the case under semiactive control based on the artificial neural networks (NARX), respectively.

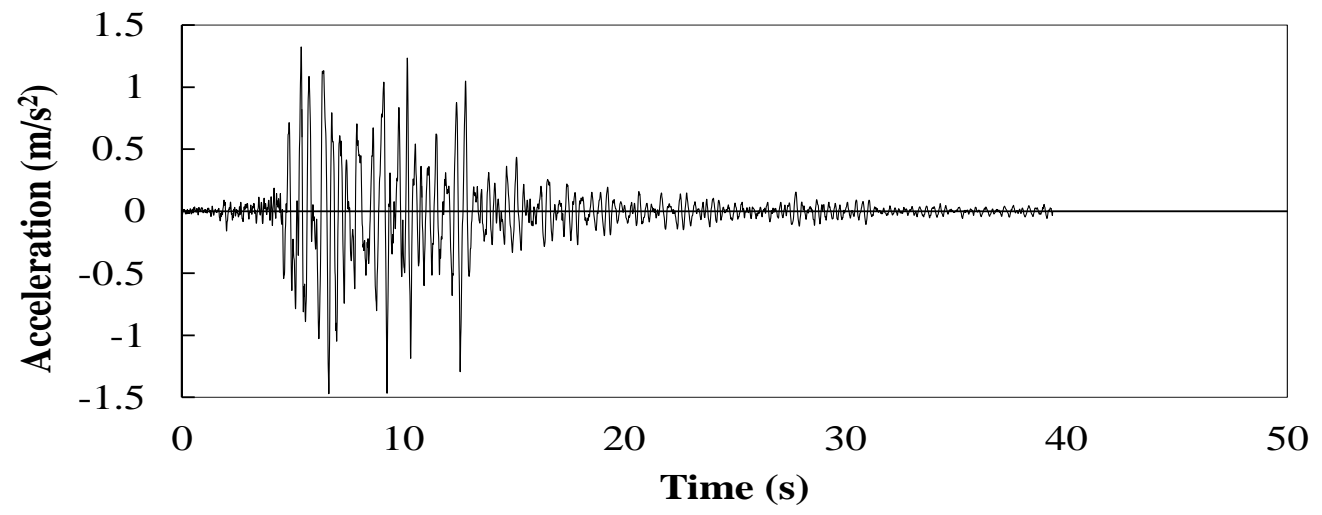

Figure 7. Registration of accelerogram. Source: The authors. 

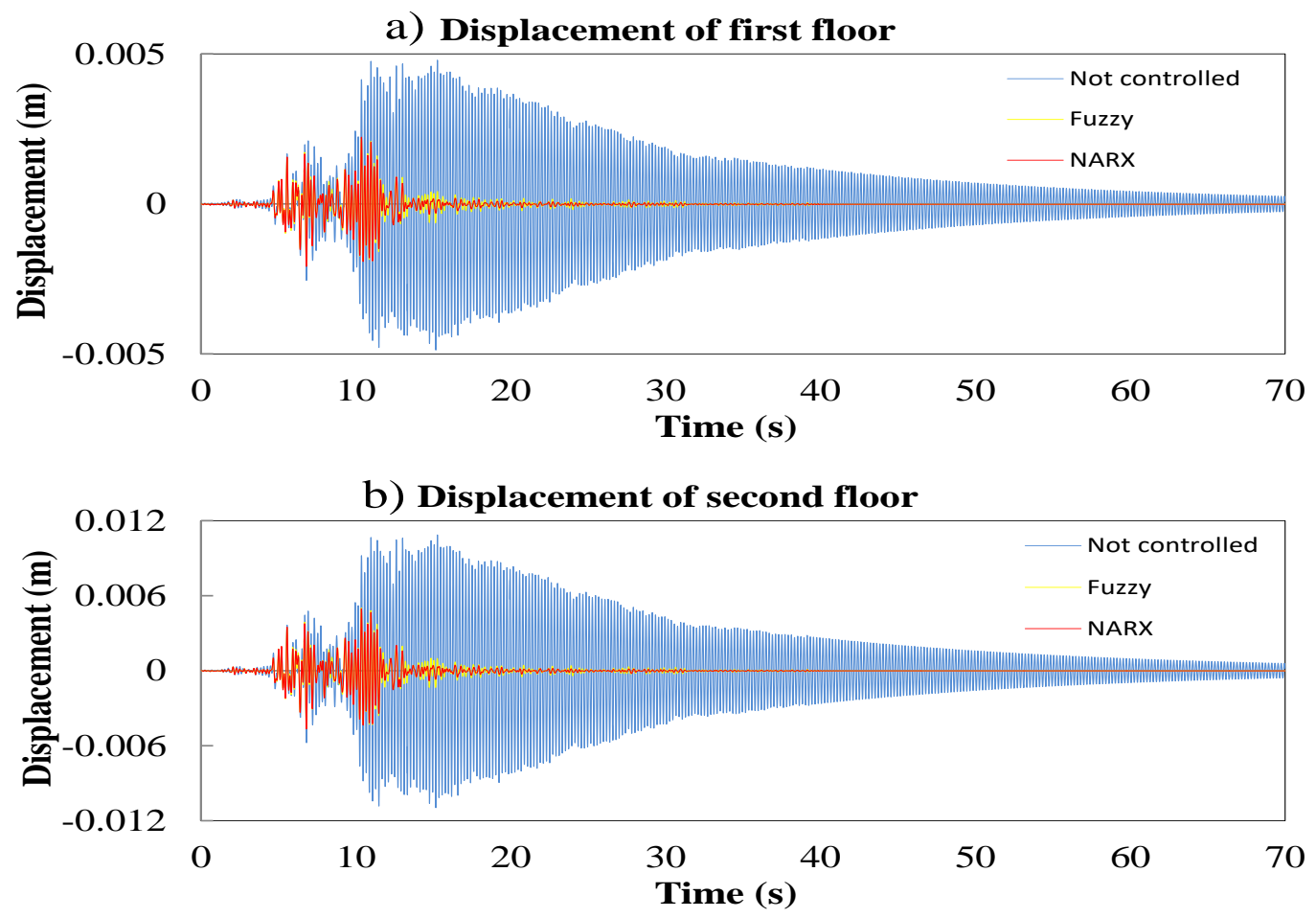

Figure 8. Displacements in the structure in the case without control and in the cases with controls based on ANN and Fuzzy logic: a) 1st floor, and b) 2nd floor. Source: The authors.

Table 4 shows a summary of the results obtained after analyzing Figure $8 \mathrm{a}$ and 8b, for the two-floor structure.

Table 4. Displacements in the structure.

\begin{tabular}{lllll}
\hline \hline \multirow{2}{*}{ Structure } & $\begin{array}{l}\text { Absolute } \\
(\mathrm{cm})\end{array}$ & values & \multicolumn{2}{l}{ RMS values $(\mathrm{cm})$} \\
\cline { 2 - 5 } & $\begin{array}{l}\text { 1st } \\
\text { floor }\end{array}$ & $\begin{array}{l}\text { 2nd } \\
\text { floor }\end{array}$ & $\begin{array}{l}\text { 1st } \\
\text { floor }\end{array}$ & $\begin{array}{l}\text { 2nd } \\
\text { floor }\end{array}$ \\
\hline Not & 0.49 & 1.10 & 0.14 & 0.32 \\
controlled & & 0.50 & 0.02 & 0.06 \\
Fuzzy & 0.22 & 0.50 & 0.02 & 0.05 \\
NARX & 0.22 & 0.50 \\
\hline \hline
\end{tabular}

Source: The authors.

Accordingly, the maximum displacements in both floors occur when the structure is without any type of control. In absolute values, the displacements in the first and second floor were $0.49 \mathrm{~cm}$ and $1.1 \mathrm{~cm}$, respectively. In order to provide a more general picture of the dynamic response, the corresponding RMS (Root Mean Square) values were also determined. Hence, the RMS displacement for the first floor was $0.14 \mathrm{~cm}$ and for the second one was 0.32 $\mathrm{cm}$. It is important to notice that RMS values characterize the central tendency of the response values with time for each model characteristic.

In Table 4, the absolute values of the displacements were basically the same for the Fuzzy and NARX controlled responses, but a reduction of $55 \%$ is observed when comparing these displacements with the response without control for the two floors. A further reduction is observed for the RMS displacement values, in which for the first floor achieved $86 \%$ and $84 \%$ for the second. Therefore, it is noticed that the reduction in the responses of the Fuzzy controlled structure undergoing seismic motion are very similar to the responses associated with the NARX managing control. 

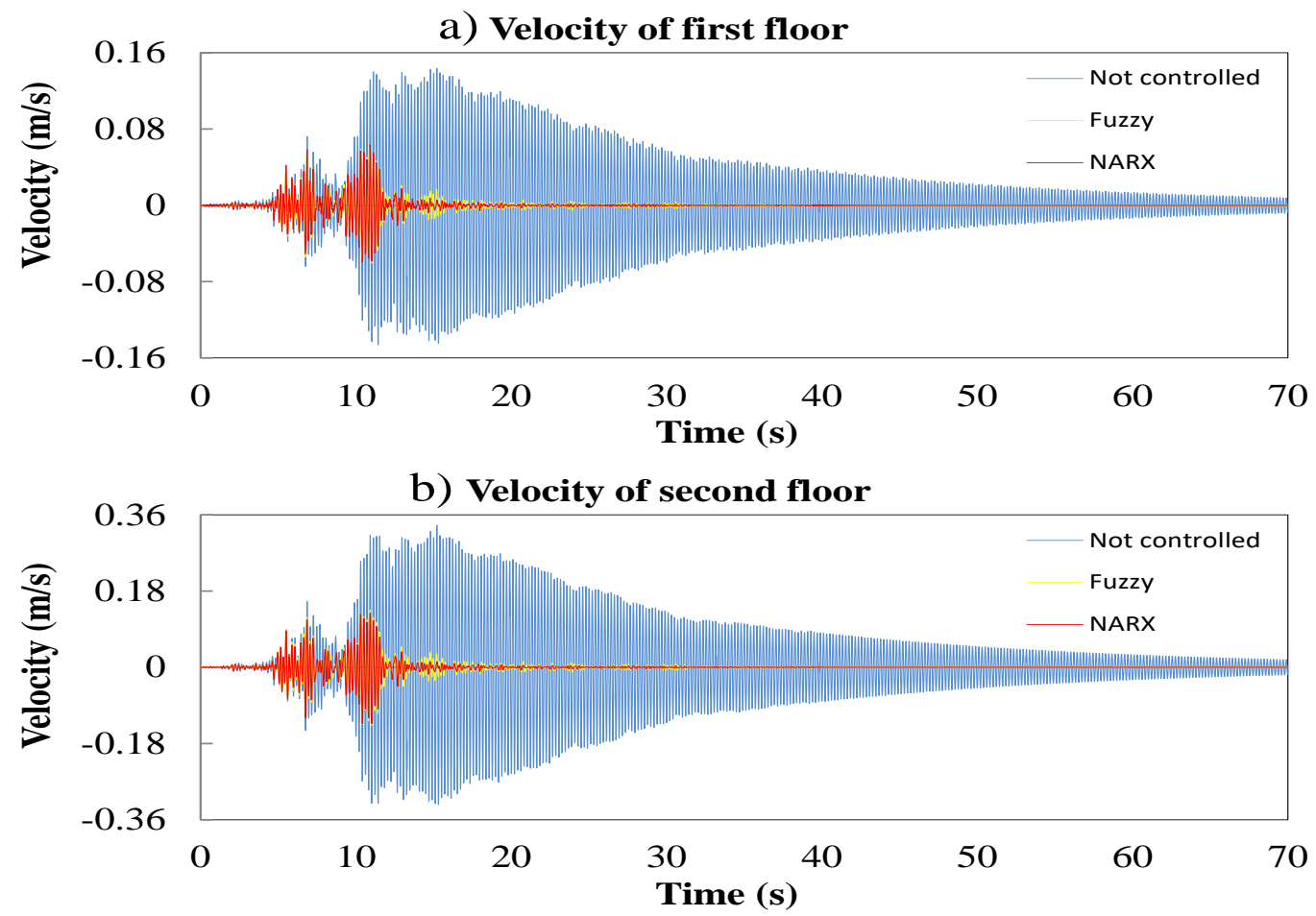

Figure 9. Velocities in the structure in the case without control and in the cases with controls based on ANN and Fuzzy logic: a) 1st floor, and b) 2nd floor. Source: The authors.

Velocity is the second response parameter investigated herein. Figure $9 \mathrm{a}$ and $9 \mathrm{~b}$ show the velocity records for first and second floors. Correspondingly, Table 5 shows absolute and RMS values for the velocities.

Table 5. Velocities in the structure.

\begin{tabular}{lllll}
\hline \hline \multirow{2}{*}{ Structure } & $\begin{array}{l}\text { Absolute } \\
(\mathrm{cm} / \mathrm{s})\end{array}$ & values & $\begin{array}{l}\text { RMS } \\
(\mathrm{cm} / \mathrm{s})\end{array}$ & values \\
\cline { 2 - 5 } & $\begin{array}{l}\text { 1st } \\
\text { floor }\end{array}$ & $\begin{array}{l}\text { 2nd } \\
\text { floor }\end{array}$ & $\begin{array}{l}1 \mathrm{st} \\
\text { floor }\end{array}$ & $\begin{array}{l}\text { 2nd } \\
\text { floor }\end{array}$ \\
\hline $\begin{array}{l}\text { Not } \\
\text { controlled }\end{array}$ & 14.66 & 33.57 & 4.35 & 9.89 \\
Fuzzy & 6.22 & 13.80 & 0.72 & 1.65 \\
NARX & 6.39 & 12.81 & 0.69 & 1.57 \\
\hline \hline
\end{tabular}

Source: The authors.

The absolute maximum velocities without control were $14.66 \mathrm{~cm} / \mathrm{s}$ on the first floor and $33.57 \mathrm{~cm} / \mathrm{s}$ on the second floor, and the corresponding RMS velocities of these floors were $4.35 \mathrm{~cm} / \mathrm{s}$ and $9.89 \mathrm{~cm} / \mathrm{s}$, respectively. After controlling the structural responses, significant reductions in velocity values are also observed. For Fuzzy control, the velocity in absolute values for the first and second floors reduces $57 \%$ and $59 \%$, respectively. A slightly difference is observed for the NARX controlled response, the corresponding absolute displacement values are reduced
$56 \%$ for the first floor and $62 \%$ for the second. Comparing the RMS values for the velocity, a reduction of $83 \%$ is observed for the first and second floor for the Fuzzy controlled system, and for NARX controlled the reduction for the speed in both floors $84 \%$. Basically, both control strategies provide similar structural responses.

Finally, the third response parameter investigated is the acceleration. In this regard, Figures 10a and 10b show the acceleration records for the first and second floors, and Table 6 summarizes the absolute and RMS values for the accelerations. As a result, the absolute maximum acceleration without control was $4.85 \mathrm{~m} / \mathrm{s}^{2}$ on the first floor and $10.17 \mathrm{~m} / \mathrm{s}^{2}$ on the second floor. The RMS acceleration without control was $1.34 \mathrm{~m} / \mathrm{s}^{2}$ and $3.04 \mathrm{~m} / \mathrm{s}^{2}$ on the first and second floors, respectively. As expected, a significant reduction in the acceleration values is achieved after applying the control strategies. For Fuzzy control, the acceleration in absolute values for the first and second floor was reduced $56 \%$ and $60 \%$ respectively. Once again, the differences in the acceleration values are very small when comparing both control strategies. For the NARX controlled system, the reductions in the accelerations were $53 \%$ for the first, and $58 \%$ for the second floor. Regarding the RMS acceleration values, a reduction of $83 \%$ is achieved for the first and second floors for the Fuzzy controlled system, and for NARX controlled the reduction for the acceleration in both floors is $83 \%$. Similarly to the velocity responses, both control strategies provide a 
similar effect on the acceleration diagram for the two floors.
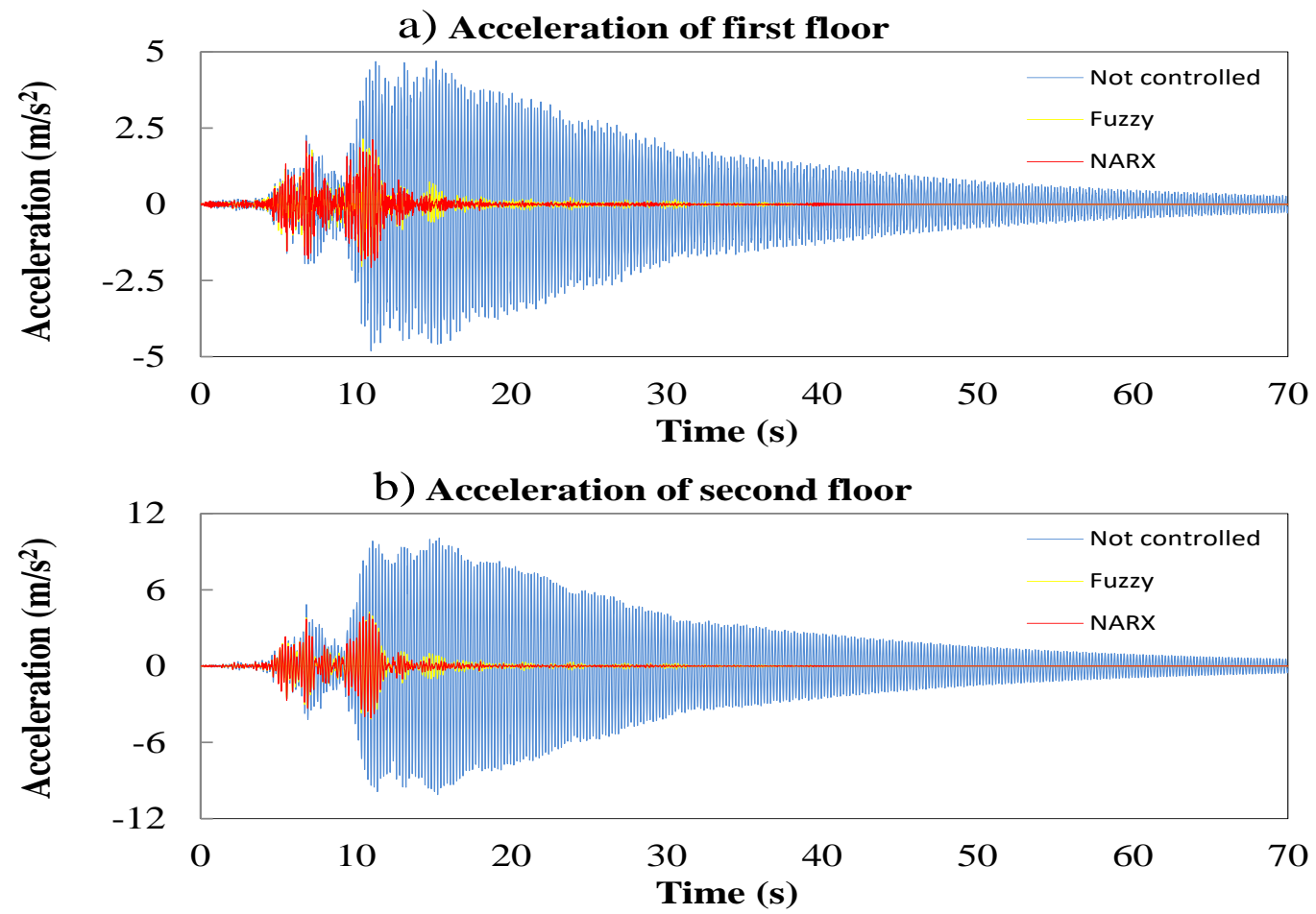

Figure 10. Accelerations in the structure without control and with controls based on ANN and Fuzzy logic:a) 1st floor, and b) 2nd floor. Source: The authors.

Table 6. Accelerations in the structure.

\begin{tabular}{lllll}
\hline \hline \multirow{2}{*}{ Structure } & $\begin{array}{l}\text { Absolute } \\
\left(\mathrm{cm} / \mathrm{s}^{2}\right)\end{array}$ & values & $\begin{array}{l}\text { RMS } \\
\left(\mathrm{cm} / \mathrm{s}^{2}\right)\end{array}$ & values \\
\cline { 2 - 5 } & $\begin{array}{l}\text { 1st } \\
\text { floor }\end{array}$ & $\begin{array}{l}\text { 2nd } \\
\text { Floor }\end{array}$ & $\begin{array}{l}\text { 1st } \\
\text { floor }\end{array}$ & $\begin{array}{l}\text { 2nd } \\
\text { Floor }\end{array}$ \\
\hline Not & 485.59 & 1017.3 & 134.86 & 304.21 \\
controlled & 8 & & 50.59 \\
Fuzzy & 230.56 & 424.08 & 23.46 & $\begin{array}{l}50.59 \\
\text { NARX }\end{array}$ \\
\hline \hline
\end{tabular}

Source: The authors.

As mentioned above, it is worth noticing that the damped responses for the Fuzzy controlled structure under seismic motion are very similar to the responses associated with the NARX managing control strategy.

\subsection{Performance indexes}

For a better evaluation of the results obtained herein from the numerical model, four performance indexes are defined in Table 7. The first three performance indexes $\left(I_{l}\right.$, $I_{2}$ and $I_{3}$ ) are normalized measurements of the peaks of displacements, velocities and accelerations of each floor. The fourth index $\left(I_{4}\right)$ is the peak displacement between the normalized floors.

Table 8 and Figure 11 present the values of the indexes obtained by the control strategies in this study. The performance indexes of the system indicate the effective performance of the controllers throughout the system. For this case of specific loading, the equilibrium between the analyzed control strategies can be observed, particularly in indexes $I_{1}$ and $I_{4}$, although the numbers produced by the neural networks control are slightly higher than those of the controller based on fuzzy logic, particularly on the second floor of the structure. 
Table 7. Definitions of performance indexes.

\begin{tabular}{|c|c|c|}
\hline Index & Parameters & Definition \\
\hline$I_{l}$ & $\begin{array}{l}X_{i}(t) \text { : Relative displacement of each floor of } \\
\text { the controlled system } \\
X_{\max }: \text { Maximum displacement of the system } \\
\text { without control }\end{array}$ & $\max _{t, i}\left(\frac{\left|X_{i}(t)\right|}{X_{\max }}\right)$ \\
\hline$I_{2}$ & $\begin{array}{l}\dot{X}_{i}(t) \text { : Relative velocity of each floor of the } \\
\text { controlled system } \\
\dot{X}_{\text {max }}: \text { Maximum velocity of the system } \\
\text { without control }\end{array}$ & $\max _{t, i}\left(\frac{\left|\dot{X}_{i}(t)\right|}{\dot{X}_{\max }}\right)$ \\
\hline$I_{3}$ & $\begin{array}{l}\ddot{X}_{i}(t) \text { : Relative acceleration of each floor of the } \\
\text { controlled system } \\
\ddot{X}_{\text {max }}: \text { Maximum acceleration of the system } \\
\text { without control }\end{array}$ & $\max _{t, i}\left(\frac{\left|\ddot{X}_{i}(t)\right|}{\ddot{X}_{\max }}\right)$ \\
\hline$I_{4}$ & $\begin{array}{l}d_{i}(t) \text { : Relative displacement between floors of } \\
\text { the controlled system } \\
d_{\text {max }} \text { : Displacement of the relative peak } \\
\text { between floors of the system without control }\end{array}$ & $\max _{t, i}\left(\frac{\left|d_{i}(t)\right|}{d_{\max }}\right)$ \\
\hline
\end{tabular}

Source: The authors.

Table 8. Magnitudes of the performance indexes.

\begin{tabular}{lllllllll}
\hline \hline \multirow{2}{*}{ Control } & \multicolumn{2}{c}{$I_{1}$} & \multicolumn{2}{c}{$I_{2}$} & \multicolumn{3}{c}{$I_{3}$} & \multicolumn{2}{c}{$I_{4}$} \\
\cline { 2 - 9 } Strategy & 1st & 2nd & 1st & 2nd & 1st & 2nd & 1st & 2nd \\
& Floor & Floor & Floor & Floor & Floor & Floor & Floor & Floor \\
\hline ANN & 0.4490 & 0.4545 & 0.4359 & 0.3816 & 0.4418 & 0.4032 & 0.4490 & 0.4553 \\
FL & 0.4487 & 0.4558 & 0.4245 & 0.4110 & 0.4748 & 0.4168 & 0.4487 & 0.4630 \\
\hline \hline
\end{tabular}

Source: The authors.
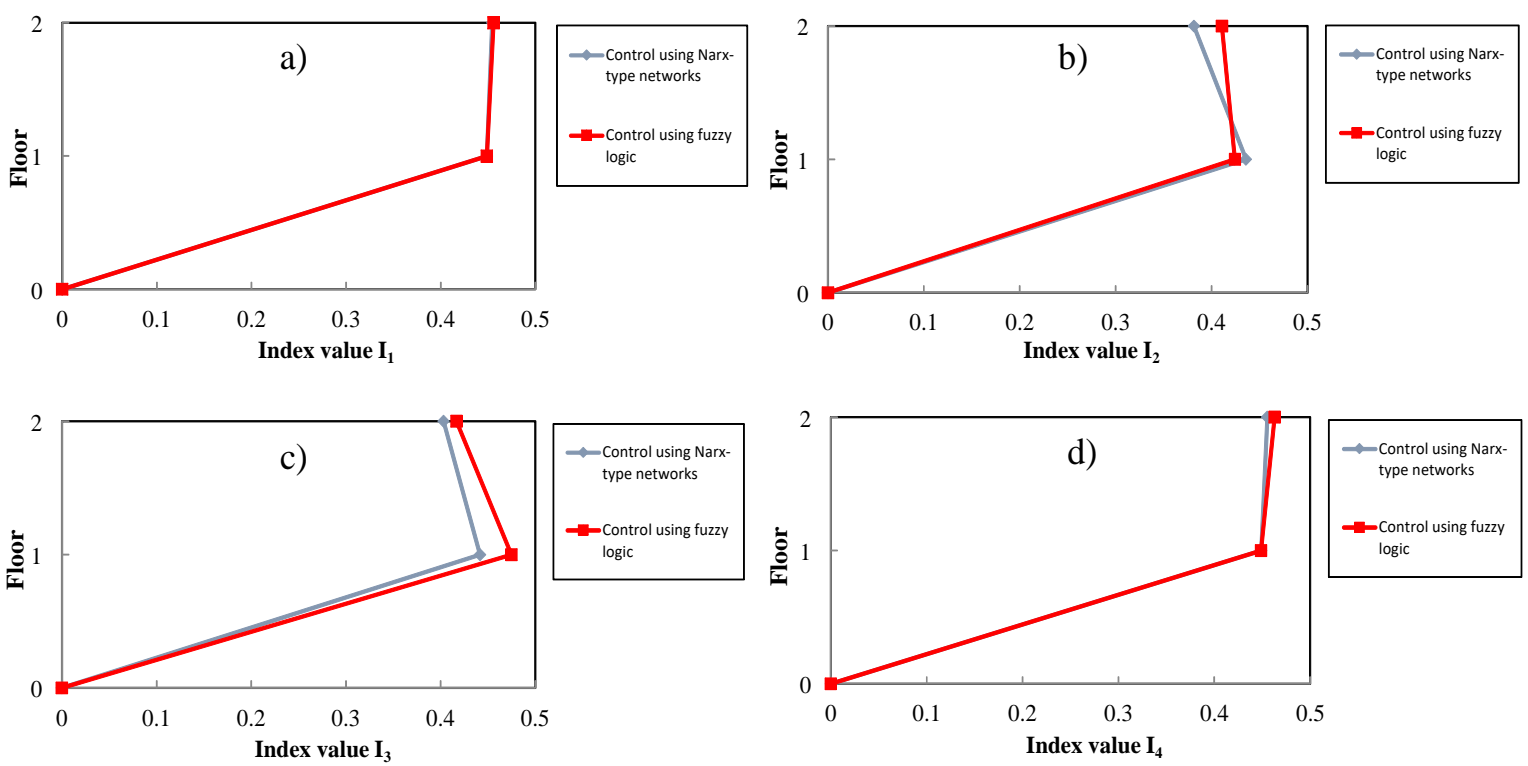

Figure 11. Performance indexes associated with the control strategies: a) $I_{1}$, b) $I_{2}$, c) $I_{3}$ and d) $I_{4}$. Source: The authors. 
Figure 12 displays certain characteristic patterns for the voltage variations produced by the control strategies. In the case of the controller based on neural networks, as the excitation applied to the structure increases, the voltage applied to the control mechanism increases until reaching the established signal limit. The signal command produces values ranging from 0 to 2.5 volts. The controller based on fuzzy logic displays behavior that closely reflects the varying excitation applied to the structure. Thus, the range of voltages remains practically constant during the time the acceleration is varying. This voltage generally ranges between 0.4 and 1.1 volts, although voltages lower than 0.4 volts were observed at many times in the test. In addition, the voltage applied by the fuzzy controller on the dampers only exceeds the maximum voltage when the excitation increases and reaches a maximum, i.e. the limit of 2.5 volts in this study.

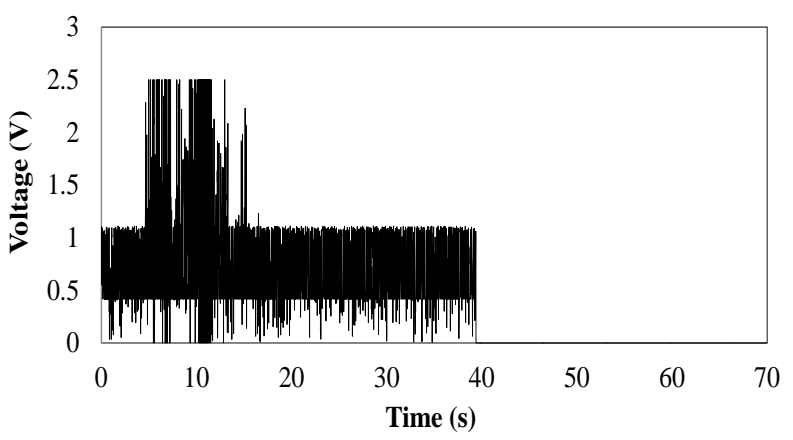

b)

Figure 12. Voltages applied to MR dampers: a) control based on neural networks and b) control based on fuzzy logic. Source: The authors.

Figure 13 presents the plot of the damper forces exerted by the controllers in the time-domain. The plot suggests the way in which the force applied by the MR dampers in the ANN-based control strategy constantly reaches the maximum force delivered by the energy-dissipating devices. This behavior is not as evident in the control strategy based on fuzzy logic: the damping force varies more; this behavior is consistent with that of the voltage. This difference may be the primary explanation for the slightly better performance of controllers based on neural networks in terms of more-efficient energy dissipation and control of vibrations.

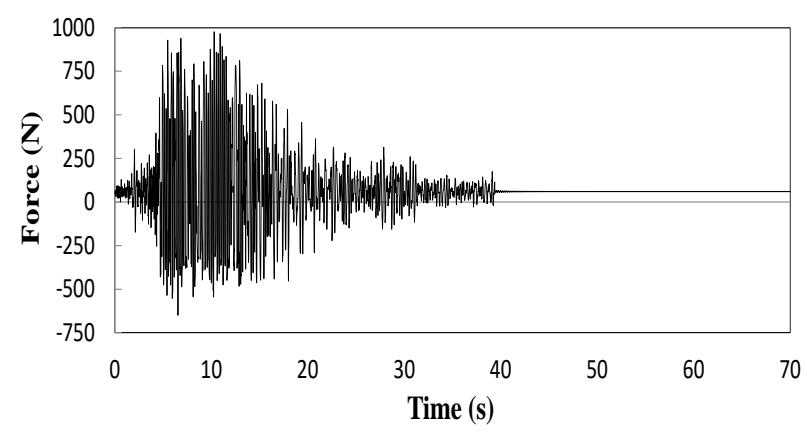

a)

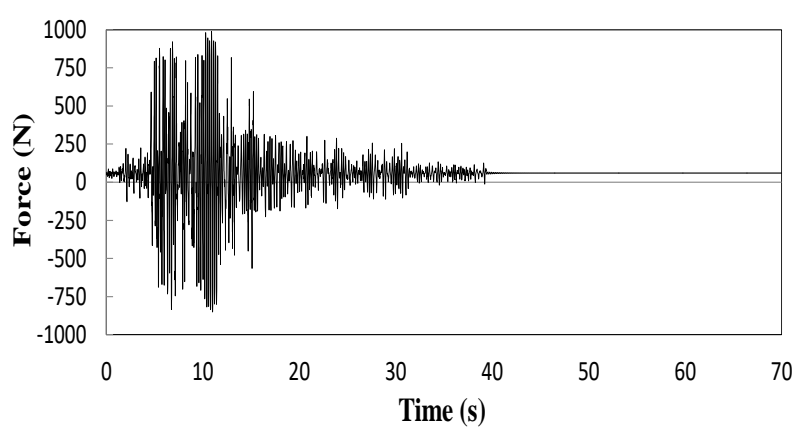

b)

Figure 13. MR damper force in time domain for the controller based on: a) neural networks, and b) fuzzy logic. Source: The authors. 


\section{CONCLUSIONS}

In this study, a numerical model was developed in which the performance of two semi-active control strategies based on MR dampers was analyzed. The algorithms that ruling the two examined controllers are based on artificial neural networks and fuzzy logic and were efficient, robust and safe tools in managing the MR dampers. The different analyzed control strategies were sufficiently competent at reducing the response of the studied frame structure, thus confirming the potential for using such semi-active systems to control structures.

The numerical analysis indicated that the control projects based on intelligent systems produce similar reductions in certain response functions, particularly with regard to displacement and velocity of the first floor. The ANNbased controller, however, was more efficient in reducing the response peaks and RMS acceleration of the first floor and the displacement, velocity and acceleration of the second floor. The better performance of the neural network control may be explained by its continuous production of high control forces, which produces greater energy dissipation. The predictive and inverse models acted properly, i.e. in a synchronized and competent manner, despite the complexities of the problem and the solution. Perhaps the greatest flaw in this control alternative is the excessive processing time, which makes its execution more difficult in real time or increases the cost of implementing the design because it requires a great deal of processing power to solve the problem rapidly.

The control project based on fuzzy logic as a command signal selection tool may be the most balanced control strategy. This controller clearly combines noticeable efficiency, fast processing and simplicity. In practice, the control algorithm based on fuzzy sets may be easily implemented due to the heuristics of the system to be managed. A primary disadvantage may be the inference system's decision-making based on the velocity and displacement, which are derived from the integration of the acceleration, and thus there may be noise and low frequencies that would need to be removed using a highpass filter.

\section{Acknowledgements}

The authors acknowledge the support provided by the University of Brasília (Universidade de Brasília), the Universidad Nacional de Colombia, Medellin Campus, and the National Council for Scientific and Technological Development (Conselho Nacional de Desenvolvimento Científico e Tecnológico - $\mathrm{CNPq}$ ) for the development of the present study.

\section{Nomenclature}

\begin{tabular}{|c|c|}
\hline Symbol & Description \\
\hline ANN & Artificial neural network \\
\hline$f(n)$ & $\begin{array}{l}\text { Control force of output in the } \\
\text { prediction model }\end{array}$ \\
\hline$F(t)$ & Force applied by the MR dampers \\
\hline$f(t)$ & $\begin{array}{l}\text { Force calculated by the prediction } \\
\text { model }\end{array}$ \\
\hline FL & Fuzzy logic \\
\hline NARX & $\begin{array}{c}\text { Nonlinear autoregressive exogenous } \\
\text { model }\end{array}$ \\
\hline NL & Negative large \\
\hline NM & Negative medium \\
\hline NS & Negative small \\
\hline$n_{d}$ & Linear function of displacement \\
\hline$n_{v}$ & Linear function of velocity \\
\hline PL & Positive large \\
\hline $\mathrm{PM}$ & Positive medium \\
\hline PS & Positive small \\
\hline$S(n)$ & Neural networks entries \\
\hline$V(t)$ & Voltage to apply in the MR damper \\
\hline$v(n)$ & Output voltage of the inverse model \\
\hline$X(t)$ & Displacement vector of the structure \\
\hline$\dot{X}(t)$ & Velocity vector of the structure \\
\hline$\ddot{X}(t)$ & Acceleration vector of the structure \\
\hline$\ddot{\mathrm{U}}_{\mathrm{g}}(\mathrm{t})$ & Ground motion \\
\hline $\mathrm{ZO}$ & Zero \\
\hline
\end{tabular}

\section{REFERENCES}

[1] Y. Kim, R. Langari, S. Hurlebaus. "Semiactive nonlinear control of a building with magnetorheological damper system". Mechanical systems and signal processing, volume 23, no. 2, pp. 300-315, Feb. 2009.

[2] G. Yang. "Large-Scale Magnetorheological Fluid Damper for Vibration Mitigation: Modeling, Testing and Control", PhD Thesis, Department of Civil Engineering and Geological Sciences, University of Notre Dame, Indiana, USA, 2001. 
[3] S. Dyke. "Acceleration feedback control strategies for active and semi-active control systems: modeling, algorithm development, and experimental verification", $\mathrm{PhD}$ Thesis, Department of Civil Engineering and Geological Sciences, University of Notre Dame, Indiana, USA, 1996.

[4] C.M. Dias. "Fuzzy Control of Magnetorheological Dampers for Vibration Reduction of Seismically Excited Structures", Ph.D. Thesis, Florida State University, Florida, USA, 2005.

[5] R. Ehrgott, S. Masri. "Modeling the oscillatory dynamic behavior of electrorheological materials in shear". Smart materials and structures, vol 1, no. 4, pp.275-285, 1992.

[6] N. McClamroch, H. Gavin. "Electrorheological dampers and semi-active structural control", 34th conference on decision \& control, New Orleans, USA, 1995.

[7] H. Gavin, R. Hanson, F. Filisko. "Electrorheological dampers part II: testing and modeling". Journal of applied mechanics, vol. 63, no. 2, pp.676-682, Sep. 1996.

[8] X. Song, M. Ahmadian, S. "Southward. Modeling magnetorheological dampers with application of nonparametric approach". Journal of intelligent material systems and structures, vol. 16, pp.421-432, May. 2005.

[9] D. Wang, W. Liao. "Neural network modeling and controllers for magnetorheological fluid dampers", the international fuzzy systems conference, Melbourne, Australia, 2001.

[10] P. Xia. "An inverse model of MR damper using optimal neural network and system identification". Journal of sound and vibration, vol. 266, no. 5, pp.10091023, Oct. 2003.

[11] D. Wang, W. Liao. "Modeling and control of magnetorheological fluid dampers using neural networks". Smart materials and structures, vol. 14, no. 1, pp. 111-126, Dec. 2004.

[12] I. H. Vadtala, D. P. Soni, D. G. Panchal. "Semiactive control of a benchmark building using neuroinverse dynamics of MR damper". Procedia Engineering, vol. 51, pp. 45-54, 2013.

[13] D. T. Liem, D. Q. Truong, K. K. Ahn. "Hysteresis modeling of magneto-rheological damper using selftuning Lyapunov-based fuzzy approach". International Journal of Precision Engineering and Manufacturing, vol. 16, no. 1, pp. 31-41, 2015.
[14] M. E. Uz, M. N. Hadi. "Optimal design of semi active control for adjacent buildings connected by MR damper based on integrated fuzzy logic and multiobjective genetic algorithm". Engineering Structures, vol. 69, pp.135-148, 2014.

[15] Y. J. Cha, A. K. Agrawal, B. M. Phillips, B. F. Spencer. "Direct performance-based design with 200kN MR dampers using multi-objective cost effective optimization for steel MRFs". Engineering Structures, vol. 71, pp. 60-72, 2014.

[16] Y. Kim, A. A. Mahajan. "Smart Control of Seismically Excited Highway Bridges". In Computational Methods in Earthquake EngineeringSpringer International Publishing. pp. 387-403, 2017.

[17] Stanway, R., Sproston, J., Stevens, N. "Non-linear identification of an electro-rheological vibration damper", Symposium on identification and system parameter estimation, York, England, 1985.

[18] R. Stanway, J. Sproston, N. Stevens. "Non-linear modeling of an electro-rheological vibration damper". Journal of Electrostatics, vol. 20, no. 2, pp.167-184, Dec. 1987.

[19] D. Gamota, F. Filisko. "Dynamic mechanical studies of electrorheological materials: Moderate frequencies". Journal of Rheology, vol 35, no. 3, pp.399-425, Nov, 1991.

[20] Jr. Spencer, B.F.; S.J. Dyke, M.K. Sain, J.D. Carlson. "Phenomenological model of a magnetorheological damper". Journal of Engineering Mechanics, vol. 123, no. 3, pp.230-238, Mar. 1997.

[21] H. G. S. Acevedo, J. Uscátegui, S. Gómez. "Metodología para la detección de fallas en una estructura entramada metálica empleando las técnicas de análisis modal y PSO”. Revista UIS Ingenierías, vol.16, no. 2, pp. 43-50, 2017.

[21] J. Carlson, Jr. Spencer. "Magneto-rheological fluid dampers: scalability and design issues for application to dynamic hazard mitigation", The 2nd workshop on structural control: Next generation of intelligent structures, China, Sep, 1996.

[22] F. Gordaninejad, M. Saiidi, B. Hansen, F. Chang. "Magnetorheological fluid dampers for control of bridges". The $2^{\text {nd }}$ World Conference on Structural Control, Chichester, U.K, 1999.

[23] L. Jansen, S. Dyke. "Semiactive control strategies for MR dampers: Comparative study". Journal of 
Engineering Mechanics, vol. 126, no. 8, pp.795-803, Aug. 2000.

[24] Y. Liu, F. Gordaninejad, C. Evrensel, G. Hitchcock. "Experimental Study on Fuzzy Logic Vibration Control of a Bridge Using Fail-Safe Magneto-Rheological Fluid Dampers", Smart Structures and Materials 2001: Smart Systems for Bridges, Structures, and Highways,, vol. 4330, 2001.

[25] M. Basili. "Controllo semi attivo di strutture adiacenti mediante dispositivi magnetoreologici: teoria, sperimentazione e modellazione", Ph.D. Thesis, Università degli studi di Roma "La Sapienza", Roma, Italy, 2006.

[26] G. Yan, L. Zhou. "Integrated fuzzy logic and genetic algorithms for multi-objective control of structures using MR dampers". Journal of Sound and Vibration, vol. 296, no. 1-2, pp. 368-382, Sep. 2006.

[27] P. Lin, P. Roschke, C. Loh. "Hybrid base-isolation with magnetorheological damper and fuzzy control". Struct. control health monit, vol. 14, no. 1, pp. 384-405, Mar. 2006.

[28] R.B. Carneiro. "Semi-active control of vibrations in structures using magnetorheological damper", Ph.D. Thesis, University of Brasilia, Brasilia, Brazil, 2009.

[29] H. Metered, P. Bonello, S. Oyadiji. "The experimental identification of magnetorheological dampers and evaluation of their controllers". Mechanical Systems and Signal Processing, vol. 24, no. 4, pp. 976994, May. 2010.

[30] L.A. Lara. "Study of semi-active control algorithms applied to magnetorheological dampers", Ph.D. Thesis, Department of Civil Engineering, University of Brasília, Brasilia, Brazil, 2011.

[31] S. Haykin. "Redes Recorrentes Dirigidas Dinamicamente", em Redes neurais princípios e prática. $2^{\text {nd }}$ edição. São Paulo, Brazil: Bookman, cap. 15, pp. 787843.

[32] X. He, H. Asada. "A new method for identifying orders of input-output models for nonlinear dynamic systems", American Control Conference, San Francisco, California, USA, pp. 2520-2523, 1993.

[33] K. Levenberg. "A method for the solution of certain non-linear problems in least squares", Quart. Appl. Math., vol. 2, no. 2, pp. 2164-2168, Jul. 1944.
[34] D.W Marquardt. "An algorithm for least-squares estimation of nonlinear parameters", Journal of the society for industrial and applied mathematics, vol. 11, no. 2, pp. 431-441, Jun. 1963.

[35] L. Lara, J. Brito, Y. Valencia. "Structural control using magnetorheological dampers governed by predictive and dynamic inverse models", Dyna, vol 81, no.188, pp.191-198, 2014.

[36] M. Aldawod, B. Samali,, F. Naghdy, K. Kwok. "Active control of a long wind response of tall building using a fuzzy controller", Engineering structures, vol. 23, no. 11, pp.1512-1522, Nov. 2001.

[37] F. Marazzi, G. Magonette. "Active and semi-active control of structures: A comparison", European meeting on intelligent structures, Italia, 2001.

[38] A. Contento, V. Gattulli, M. Lepidi, F. Potenza. Identificazione di modelli per un protótipo sperimentale di telaio tridimensionale com controventi semi-attivi, Università degli studi dell'Aquila, Technical Report no.2, 2006.

[39] Lord technical data RD-1005-3 Damper, Lord Corporation, Technical data, Cary, USA, 2006. 